\title{
Developing a Public Health Monitoring System in a War-torn Region: A Field Report From Iraqi Kurdistan
}

\author{
Stefania Moramarco, PhD; (1) Faiq B. Basa, PhD; Haveen H. Alsilefanee, MD; \\ Sivar A. Qadir, MD; Leonardo Emberti Gialloreti, MD, PhD
}

\section{ABSTRACT}

Wars, terrorism, and embargos destroyed facilities and shattered the public health system of Iraq. Today, there is limited documented knowledge about the health situation of the Iraqi population, particularly because health data are not systematically collected. Therefore, the capacity of the health system to address the major health problems of the population is considerably reduced. This report describes the implementation, started in 2015 , of an electronic system for epidemiological monitoring and health surveillance, designed to collect and manage health care data in Iraqi Kurdistan. The aim of the program is to network all of the main health centers and hospitals of the region, then of the whole country, and to train medical and administrative staff in the management and analysis of health data. In countries recovering from war, a functioning health monitoring system is essential in guiding the development of appropriate public health interventions, a key instrument to prepare the health system to respond to future emergencies.

Key Words: emergency preparedness, health-monitoring system, Iraq, rebuilding public health systems, war and terrorism

$\mathrm{D}$ uring the 1970s and 1980s, the Iraqi health system was known as one of the most advanced in the Eastern Mediterranean Region. Its health indicators were among the best of the area. However, the last 30 years of communal tensions, wars, terrorism, and embargos destroyed facilities and shattered the whole health system. ${ }^{1}$ Health infrastructures were left in a state of abandonment, and medical personnel were killed or forced to flee. Consequently, Iraq experienced a steep increase in mortality, which can be attributed to direct violence but also to indirect causes, such as failures of health, sanitation, and other systems. ${ }^{2}$ Since May 2014, Iraq's precarious political balance has been made even more unstable by the conquest of entire regions by the so-called "Islamic State" (ISIS). In 2017, the Iraqi state resumed the initiative, reconquesting the areas held by ISIS. During the struggle, the Kurdistan Region of Iraq (KRI) - an autonomous region of Iraq since 1991 became a safe haven for hundreds of thousands of refugees and internally displaced people (IDPs). This has caused consistent pressures on local services, as well as on health system performance. When the government of Iraq retook the areas previously held by ISIS, IDPs started to return to their homes. Nevertheless, at the beginning of 2019, KRI was still hosting large numbers of IDPs. ${ }^{3}$ The complex political framework has not yet allowed to fully rebuild those institutions necessary to administer the country, including the public health system.

\section{NARRATIVE}

The actual health situation of the Iraqi population is poorly documented, particularly because health data are not systematically collected and are mostly on paper rather than collected electronically, with few non-aggregated data available or in a format suited for analysis or management ${ }^{4}$ and with little health-related and epidemiological information. Data are not being routinely used for health planning, and the impact of the provided care is not efficiently monitored or evaluated. ${ }^{5}$ In Iraq, as well as in KRI, there is no formal and institutionalized structure with the task of monitoring diseases and analyzing health care needs. ${ }^{6}$ This results in inadequate knowledge on the population's health and insufficient understanding of its needs, limited public health vision and organization, as well as lack in prevention activities and in preparedness response plans. ${ }^{7}$ Wherever possible, data are deduced from sporadic surveys, ${ }^{8}$ United Nations estimates, figures collected from neighboring countries, or from countries with similar health profiles. ${ }^{9}$ The absence of data collection systems is one of the reasons for the lack of "the capacity to deliver services that address the major health problems faced by the majority of the population 
in an equitable and sustainable manner." ${ }^{" 10}$ In order to start rebuilding a functioning public health system, there is the need to develop adequate epidemiological surveillance and health monitoring systems. ${ }^{11}$ These are the foundations deemed necessary to create a health system capable of responding promptly to present and emerging needs, as well as to adequately inform the health policies of a country or region. ${ }^{12}$

To respond to this health priority, the University of Rome Tor Vergata (Italy) and the Ministry of Health of KRI have started a collaboration to implement an electronic system for epidemiological monitoring and health surveillance. The system has been designed to manage health care data by collecting, storing, managing, and transmitting patients' electronic medical records, as diagnoses, vaccinations, births, and deaths.

The project began with a pilot in KRI in June 2015, as this Iraqi region had not been occupied by ISIS; however, the aim of the project is to set up the system in the whole country. By December 2017, 29 health centers and hospitals of KRI have been networked (about $5 \%$ of all health facilities in the region) and are routinely collecting diagnoses of all referred patients, using a data system put up on the District Health Information System 2 (DHIS 2) platform. ${ }^{13}$ DHIS 2 is an online, open-source software for the reporting of routinely collected health data, which is in use by 67 low- and middleincome countries. Within DHIS 2, data elements are organized by a geographic unit, such as district or region, and can be pooled to develop indicators, which can be displayed by means of tables, figures, or maps. The platform is extremely flexible, and, as soon as the necessary legal permissions have been obtained, the platform can be adapted to interact with other already existing international databases and surveillance systems, such as, for example, the Global Health Observatory Data Repository. Interoperability with other systems is further enhanced by the fact that disease coding is based on the 10th revision of the International Statistical Classification of Diseases and Related Health Problems (ICD-10), the internationally recognized medical classification of the World Health Organization. In order to construe the diagnosis, even if the doctor did not use English and instead Arabic or Kurdish Sorani, an ad hoc software to automatically translate and code the diagnoses has been developed. Data can be easily entered through laptops, tablets, or smartphones.

In the framework of the project, a team of local collaborators has been established. Additionally, about 700 medical doctors, statisticians, and public health officials of the region have been trained on the use of health information and epidemiological surveillance systems, as well as the ICD-10.

After having considered and evaluated the positive results obtained by the pilot project, the implementation phase of the comprehensive program was started in 2018. Beyond the 29 already active centers, 30 new ones will start collecting data
TABLE

Number of Centers Already Active and in the Process to be Activated in 2019, Distributed by Governorate

\begin{tabular}{|c|c|c|c|c|c|}
\hline \multirow[b]{2}{*}{ Governorate } & \multicolumn{2}{|c|}{$\begin{array}{c}\text { Number of Active } \\
\text { Centers }\end{array}$} & \multicolumn{2}{|c|}{$\begin{array}{c}\text { Number of Centers to } \\
\text { be Activated }\end{array}$} & \multirow[b]{2}{*}{ Tota } \\
\hline & $\begin{array}{l}\text { Health } \\
\text { Centers }\end{array}$ & Hospitals & $\begin{array}{l}\text { Health } \\
\text { Centers }\end{array}$ & Hospitals & \\
\hline Dohuk & 6 & 1 & 11 & 2 & 20 \\
\hline Erbil & 7 & 4 & 3 & 4 & 18 \\
\hline Halabja & 0 & 1 & 0 & 0 & 1 \\
\hline Sulaymaniyah & 3 & 7 & 6 & 4 & 20 \\
\hline \multirow[t]{2}{*}{ Total } & 16 & 13 & 20 & 10 & \\
\hline & \multicolumn{2}{|c|}{29} & \multicolumn{2}{|c|}{30} & 59 \\
\hline
\end{tabular}

by the end of 2019 (Table 1). The health and administrative personnel of all of these centers have already been trained in data collection, analysis, and disease classification. By April 2019, more than 300,000 disease events have been recorded in the 4 Governorates of KRI - Dohuk, Erbil, Halabja, Sulaymaniyah - and stored in the system.

The aim of the full-fledged program is (1) to expand the health monitoring system already activated through the pilot project, so to network by 2021 the approximately 120 main health centers and hospitals of the region; (2) to train health and administrative staff in the management and analysis of health monitoring system data; (3) to train highly specialized personnel on public health and computer science, to guarantee the continuity and future sustainability of the health monitoring system by handing it over in 2021 to the local Ministry of Health; and (4) to include also in the health monitoring system the private facilities, especially hospitals, which still play a significant role in the Iraqi health system. A subsequent expansion of the health monitoring system to whole Iraq is foreseen in the following years.

\section{DISCUSSION}

Amid long-lasting conflicts, Iraq and KRI have experienced rapid demographic, economic, and social changes, especially after the 2003 war, with massive consequences on the public health sector. This has led to poor health outcomes, when compared with some of the neighboring countries. ${ }^{14}$ Overwhelmed by continuous emergencies, the country could not set up a functioning health information system, making it difficult to develop health policies that meet the actual needs of the population. In fact, the main problem of health care in Iraq is the absence of planning, so that health care is still oriented toward short-term objectives, mainly focused on combating emerging diseases, without systematic prevention and health promotion activities. The few existing statistical data are mostly sample data, which cannot be used to inform health policy, to plan or identify the key issues to be addressed. A data 
and information system providing reliable health indicators is necessary for modern policy developments, as it is essential to support evidence-based decision-making and to address humanitarian help, allowing also a prompt response to future emerging needs. ${ }^{15}$ Therefore, electronic systems for epidemiological surveillance are essential to support local governments during the effective rebuilding of an efficient public health system. Those systems can act also as early warning systems, paramount for both disaster preparedness and effective post-war resilience. As the fight for the liberation of Mosul from ISIS has shown, such events can rapidly change the health picture of both the affected and neighboring areas. During the Mosul fight, hundreds of thousands of IDPs flooded in KRI from surrounding areas, adding a new burden to the public health system of the region. Only with a rapid alerting of suspected cases of diseases, especially when talking about outbreaks, the country can implement response measures to mitigate their negative impact. However, an alert system can work only if data have been regularly collected for years, so that a sudden change in disease prevalence can be immediately detected, forming the basis of an adequate evidence-based response.

\section{CONCLUSION}

A functioning health monitoring system is essential in guiding the development of appropriate public health interventions and is a key instrument to prepare the health system to respond and to cope with future emergencies. For a country like Iraq, such a system - alongside the necessary early-response interventions is the only way to manage in the medium- and long-term complex and open-ended social situations that affect population health.

\section{About the Authors}

Department of Biomedicine and Prevention, University of Rome Tor Vergata, Italy (Drs Moramarco, Emberti Gialloreti); Rizgary Hospital, Erbil, Kurdistan Region, Iraq (Dr Basa); Directorate of Health, Dohuk, Kurdistan Region, Iraq (Dr Alsilefanee); and Directorate of Health, Sulaymaniyah, Kurdistan Region, Iraq (Dr Qadir).

Correspondence and reprint requests to Stefania Moramarco, University of Rome Tor Vergata, via Montpellier 1, 00133 Rome, Italy (e-mail: stefania. moramarco@gmail.com).

\section{Acknowledgments}

The program is funded by the Italian Agency for Development Cooperation (AICS) and is developed in cooperation with the Kurdistan Regional Government and its Ministry of Health.

\section{Conflict of Interest Statement}

The authors have no conflicts of interest to declare.

\section{REFERENCES}

1. Ross AC, Moore M, Hilborne LH, et al. Strengthening health care in the Kurdistan Region of Iraq, Santa Monica, Calif.: RAND Corporation, RB-9990-KRG. 2017. https://www.rand.org/pubs/research_briefs/RB9990. html. Accessed April 7, 2019.

2. Hagopian A, Flaxman AD, Takaro TK, et al. Mortality in Iraq associated with the 2003-2011 war and occupation: findings from a national cluster sample survey by the University Collaborative Iraq Mortality Study. PLoS Med. 2013;10(10):e1001533. doi:10.1371/journal.pmed.1001533.

3. IOM, RWG, UNAMI, et al. Reasons to remain: categorizing protracted displacement in Iraq, November 2018. International Organization for Migration (IOM). 2018. https://iraq.iom.int/files/publications/ Categorizing_Protracted_Displacement_in_Iraq_2018-11_IOM_RWG_SI. pdf. Accessed October 29, 2019.

4. Ross AC, Moore M, Hilborne LH, et al. Health sector reform in the Kurdistan Region - Iraq Primary Care Management Information System, Physician Dual Practice Finance Reform, and Quality of Care Training. Kurdistan Regional Government Ministry of Planning, Ministry of Health. RAND Corporation. 2017. https:/www.rand.org/ pubs/research_reports/RR1658.html. Accessed April 7, 2019.

5. Webster PC. Iraq's health system yet to heal from ravages of war. Lancet. 2011;378(9794):863-866.

6. World Health Organization (WHO). Health systems profile - Iraq. Regional Health Systems Observatory. 2006. http://apps.who.int/ medicinedocs/documents/s17295e/s17295e.pdf. Accessed April 6, 2019.

7. Al Hilfi TK, Lafta R, Burnham G. Health services in Iraq. Lancet. 2013;381(9870):939-948.

8. IOM, UNFPA, KRSO. Demographic survey Kurdistan Region of Iraq. 2018. http://iomiraq.net/reports/demographic-survey-kurdistan-region-iraq. Accessed April 3, 2019.

9. Mokdad AH, Forouzanfar MH, Daoud F, et al. Health in times of uncertainty in the eastern Mediterranean region, 1990-2013: a systematic analysis for the Global Burden of Disease Study 2013. Lancet Glob Health. 2016;4(10):e704-713.

10. Iraqi Ministry of Health and WHO. A basic health services package for Iraq. 2009. http://applications.emro.who.int/dsaf/libcat/EMROPD_2009_109. pdf. Accessed October 29, 2019.

11. Emberti Gialloreti L, Moramarco S, Palombi L. Investing in epidemiological surveillance for recovering health system in war-torn countries. Perspect Public Health. 2019; epub.

12. Massoudi BL, Chester KG. Public health, population health, and epidemiology informatics: recent research and trends in the United States. Yearb Med Inform. 2017;26(1):241-247.

13. DHIS2 [District Health Information System 2] Version 2.31. DHIS 2 Documentation team. 2006-2019. https://www.dhis2.org/. Accessed April 6, 2019.

14. UNICEF. The State of the World's Children 2009. Statistical tables. 2009. https://www.unicef.org/sowc09/docs/SOWC09_all_tables.pdf. Accessed February 28, 2019.

15. Ministry of Planning Kurdistan Regional Government. Kurdistan Region of Iraq 2020. A vision for the future. 2013. http://www.mop.gov.krd/ resources/MoP\%20Files/Newsletter/kurdistan_region_of_iraq_2020_new. pdf. Accessed October 29, 2019. 